\title{
Uma Arquitetura Pedagógica para Construção Cooperativa de Resenhas Reflexivas no Contexto de Ensino a Distância
}

\author{
Cristiano Biancardi ${ }^{1,2}$, Crediné Silva de Menezes $^{1,3}$, Leonardo Teixeira de Freitas \\ Ribeiro Vilhagra ${ }^{2}$
}

${ }^{1}$ Programa de Pós-graduação em Informática (UFES) - Vitória, ES - Brasil

${ }^{2}$ Universidade Vila Velha (UVV) - Vila Velha, ES - Brasil

${ }^{3}$ Programa de Pós-Graduação em Informática na Educação (UFRGS) - Porto Alegre, RS - Brasil

\{cristiano.biancardi, credine, leonardotfrvilhagra\}@gmail.com

\begin{abstract}
This work proposes a Pedagogical Architecture for Cooperative Building of Reflective Review in the Distance Learning Context. It is supported by the concepts of knowledge building, cooperation, metacognition and provides, in a systematic way, situations of imbalance and reconstructions that require network interaction, active and reflective attitudes from students. For the specific features, its computational environment was defined. An experiment is also presented, carried out from a prototype, with promising results, showing the importance of the proposed approach.
\end{abstract}

Resumo. Este trabalho propõe uma Arquitetura Pedagógica para Construção Cooperativa de Resenhas Reflexivas no Contexto de Ensino a Distância. Ela é apoiada nos conceitos de construção do conhecimento, cooperação, metacognição e propicia, de uma forma sistemática, situações de desequilíbrio e reconstruções que exigem dos alunos interação em rede, atitudes ativas e reflexivas. Para as suas características específicas, foi definido o ambiente computacional. Apresenta-se também um experimento, realizado a partir de um protótipo, com resultados promissores, evidenciando a importância da abordagem proposta.

\section{Introdução}

A Educação a Distância é um exemplo clássico de modalidade disruptiva, em que novas e poderosas tecnologias digitais, aliadas às novas metodologias de aprendizagem, podem potencializar a experiência on-line e o aprendizado dos alunos (Christensen; Eyring, 2014). De acordo com Alves (2011), a Educação a Distância (EAD) constitui um recurso de incalculável importância para atender grandes contingentes de alunos, de forma mais efetiva que outras modalidades e sem riscos de reduzir a qualidade dos serviços oferecidos em decorrência da ampliação do número de alunos atendidos.

Neste contexto, um grande desafio que surge é a concepção de novas abordagens que permitam a interação e o aprendizado cooperativo (Pimentel; Fucks, 2011), envolvendo alunos, tutores e professores separados fisicamente no tempo e/ou espaço, possibilitando a construção do conhecimento (Scarmadalia; Bereiter, 2006). Não menos importante, outras demandas aparecem atreladas a estas abordagens e estão diretamente ligadas a monitorar grupos de discussão assíncronos, fornecendo aos professores informações sobre as discussões dos alunos e suporte, para orientar o envolvimento e o 
aprendizado (Pedró, 2019); apoio na avaliação de atividades e fornecimento de feedback; verificação de autoria, formação de grupos, dentre outras.

Visando a contribuir neste cenário, este trabalho propõe uma nova Arquitetura Pedagógica (AP) baseada nos princípios definidos em Carvalho, Nevado e Menezes (2005), objetivando apoiar professores, tutores e alunos no processo de ensino e aprendizagem e tendo como premissa básica a cooperação para construção de conhecimento através de uma atividade resenha reflexiva, partindo de produções individuais e evoluindo para produções coletivas. Ela propicia, de uma forma sistemática, situações de desequilíbrio e reconstruções que exigem dos alunos interações em rede, atitudes ativas e reflexivas, sendo apoiada nos conceitos de construção do conhecimento, cooperação e metacognição. Para as características específicas desta AP, foi definido o seu ambiente computacional. Apresenta-se também um experimento, realizado a partir de um protótipo, com resultados promissores, evidenciando a importância da abordagem proposta.

Este trabalho está organizado da seguinte forma: a Seção 2, Fundamentação Teórica e Trabalhos Relacionados; a Seção 3, Descrição da Arquitetura Pedagógica Proposta; a Seção 4, Descrição do Experimento; a Seção 5, Resultados e Discussões; e a Seção 6, Considerações Finais.

\section{Fundamentação Teórica e Trabalhos Relacionados}

Segundo Castro e Menezes (2011), as tecnologias não devem limitar o trabalho de professores e alunos, mas sim potencializar suas ações. Além disso, a realização de uma atividade pedagógica requer um ambiente adequado ao que será produzido e às preferências e necessidades dos participantes. Eles ainda sustentam que o uso de tecnologias para a promoção da aprendizagem cooperativa pode ser ancorado no conceito de Arquiteturas Pedagógicas (AP). Para Carvalho, Nevado e Menezes (2005), elas são definidas como "suportes estruturantes" para a aprendizagem, combinando o aparato técnico com a visão pedagógica, numa ideia ecossistêmica e são configuradas pela confluência de diferentes componentes, enfatizando-se: a abordagem pedagógica, o software de apoio, a internet, a inteligência artificial, a educação a distância e a concepção de interconexão em tempos e espaços múltiplos.

Nas referidas arquiteturas, a concepção de aprendizagem é entendida como um processo contínuo, onde o sujeito atua sobre o mundo e reflete sobre sua própria ação (metacognição), numa construção dialética (Nevado; Menezes; Vieira Júnior, 2011) a qual acontece (Piaget apud Parrat-Dayan; Trypon, 1998), quando o sujeito encontra um espaço de ação autônoma e de construção conjunta. Nesse sentido, as arquiteturas precisam fugir das formas tradicionais de ensino, pautadas em aquisição de conhecimento, em recepção passiva dos estudantes e em exercícios repetitivos, indo na direção de atividades que promovam interação em rede, autoria, desequilíbrios e reconstruções, solicitando dos estudantes atitudes ativas e reflexivas, a partir de estruturas de trabalho interativas e construtivas (Nevado; Menezes; Vieira Júnior, 2011).

De acordo com Aragon (2016), nas APs, as possibilidades interativas que as redes oferecem não podem ficar restritas à centralidade da figura do professor, sendo necessária a consolidação de uma política de envolvimento e um comprometimento dos sujeitos visando à construção coletiva que, em grande parte dos processos educativos, requer algum grau de mediação, já que uma cultura de trabalho interativo e digital ainda está por 
se estabelecer. Assim, nas APs, é necessária uma organização de trabalho que estabeleça a mediação não apenas como ação de um professor, mas sim como uma função distribuída entre os participantes, levando os aprendizes a assumirem uma posição mais ativa, exercendo mediações que são aprimoradas com o seu exercício, num movimento contínuo entre o fazer e o compreender.

Já Scardamalia e Bereiter (2006) ressaltam a relevância do desenvolvimento do conhecimento em vez da transmissão dele. Os alunos precisam ser considerados como membros de uma comunidade de construção de conhecimento no lugar de simples aprendizes, possibilitando, assim, que a construção do saber aconteça através de um esforço coletivo e cooperativo, gerando o aprendizado individual.

Como trabalhos relacionados que fornecem apoio pedagógico para a inserção de tecnologias digitais no processo de ensino, buscando otimizar os resultados obtidos na aprendizagem do indivíduo, temos: segundo Fiusa e Mocelin (2017) - a Elaboração de Histórias Coletivas, Debate de Teses, Socialização de Soluções e Auxílio na Educação de Surdos; e o EsCola (Barros e Menezes, 2016).

\section{Arquitetura Pedagógica Proposta}

A proposta deste trabalho se baseia em Carvalho, Nevado e Menezes (2007), que estabelecem o conceito de AP sustentada em três componentes: 1) Concepção pedagógica forte; 2) Sistematização metodológica buscando proporcionar aos estudantes atividades intelectuais interessantes; e 3) Suporte computacional de apoio ao processo. Nas subseções seguintes, apresentamos a arquitetura proposta.

\subsection{Concepção Pedagógica}

A concepção pedagógica desta AP se baseia em explorar os possíveis e necessários (Piaget, 1985) do aluno para a construção do seu conhecimento, a partir da elaboração de resenhas reflexivas, em uma abordagem cooperativa e metacognitiva, considerando a produção individual numa etapa preliminar.

\subsection{Sistematização Metodológica}

Buscando uma sistematização metodológica, aliada a uma preocupação efetiva da participação e contribuição de cada sujeito para o processo, foram definidos os seguintes elementos estruturantes:

i) $\mathrm{O}$ professor propõe um texto base e define os elementos norteadores para a elaboração de uma resenha reflexiva pelos alunos: identificação das ideias principais e elaboração de críticas em relação ao texto lido;

ii) Elaboração individual da resenha reflexiva;

iii) É feita uma organização dos grupos e as resenhas individuais dos integrantes de cada grupo são socializadas entre eles;

iv) Os alunos estabelecem interações em rede para realizar discussões e reflexões, tomando por base as resenhas individuais. Objetiva-se gerar possibilidades de enriquecimento do pensamento individual e coletivo e, a partir disso, criar uma nova resenha para o grupo como consequência das trocas cooperativas. O professor acompanha o envolvimento dos alunos e faz intervenções para estímulo à participação;

v) Os alunos apresentam suas percepções com respeito à autoavaliação e avaliação 
de seus pares com relação à participação e qualidade das contribuições. Também realizam a autoavaliação das resenhas individuais e do grupo baseada em critérios definidos pelo professor. Além disso, fornecem críticas e sugestões acerca da atividade desenvolvida;

vi) $\mathrm{O}$ professor e o tutor fazem o levantamento das entregas, a correção das resenhas dos grupos, a contabilização da nota final de cada aluno e fornecem o feedback com relação à produção do grupo e a participação dos indivíduos na atividade.

\subsection{Suporte Computacional}

Para as características específicas desta AP, os recursos computacionais foram definidos através de um ambiente em aplicação web, usando arquitetura cliente-servidor e sendo baseada em componentes, visando ao reuso e à integração. A Figura 1 apresenta o diagrama da arquitetura do ambiente computacional proposto.

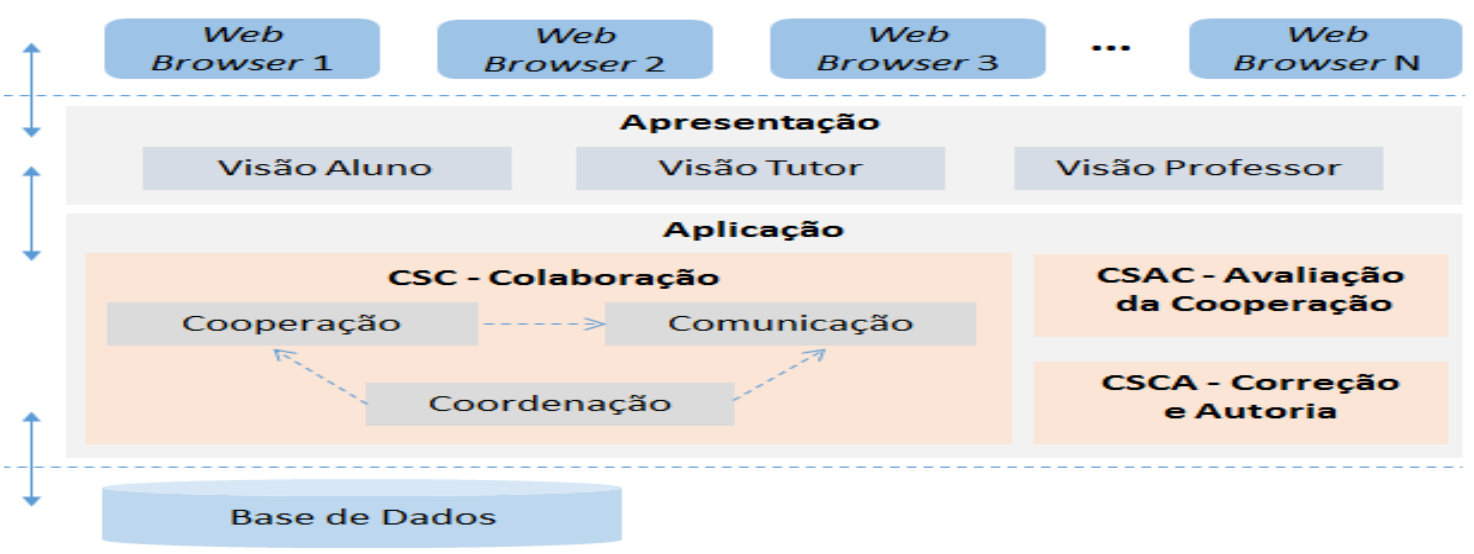

Figura 1: Diagrama de arquitetura do ambiente proposto

No ambiente, as interfaces serão personalizadas para alunos, tutores e professores, segundo seus respectivos níveis de permissão, e o acesso ocorrerá através de um navegador web. Para controlar o acesso dos usuários e suas visões ao sistema, a arquitetura prevê o componente de Apresentação, que, segundo o tipo de usuário, ativará as funcionalidades dos demais componentes na camada de Aplicação.

\subsection{Componente de Suporte à Colaboração (CSC)}

Neste trabalho, a colaboração será analisada, levando em conta o Modelo 3C proposto (Ellis et al., 1991). Este modelo tem sido usado na literatura para classificação dos sistemas colaborativos e se baseia em três componentes inter-relacionados: Comunicação (troca de informações), Coordenação (atividades a serem realizadas) e Cooperação (operação conjunta dos membros do grupo em um espaço compartilhado).

O CSC oferece suporte a cada um dos componentes do Modelo 3C. A Comunicação acontecerá através das funcionalidades de chat e fórum disponíveis, permitindo interações e discussões sobre as atividades a serem desenvolvidas. Além disso, o ambiente também suporta envio de alertas sobre prazos e pendências em atividades, baixo índice de participação e mensagens motivacionais. Relacionado à Coordenação, o ambiente disponibiliza funcionalidades de criação de atividade colaborativa, gestão de workflow entre as etapas da atividade, configurações diversas de prazos de realização, pontuação, tipos de alertas e criação de grupos de alunos. Para a Cooperação, o ambiente provê funcionalidades de gestão dos artefatos produzidos de forma individual e em grupo, controle de acesso aos artefatos do grupo, edição 
cooperativa de documentos textuais e avaliação dos pares.

\subsection{Componente de Suporte à Avaliação de Colaboração (CSAC)}

Para acompanhar o envolvimento dos participantes e realizar ações com vistas a potencializar o engajamento e a realização das atividades, torna-se fundamental mensurar e avaliar a colaboração de cada estudante e do grupo, propiciando identificar, segundo (Collazos et al., 2007): se houve colaboração, se as informações compartilhadas foram significativas e se os instrumentos contribuíram para a aprendizagem dos envolvidos. Serão aplicadas medições sobre os dados provenientes de troca de mensagens em chat e fórum. Elas são baseadas em métricas, como: número de mensagens postadas em fórum, número de respostas às mensagens em fórum e significância das mensagens relativo ao texto base para construção das resenhas. Esse contexto conta com agentes inteligentes (Russel; Norvig, 1995) para monitorar e efetuar intervenções necessárias.

\subsection{Componente de Suporte à Correção e Verificação de Autoria (CSCA)}

A correção das resenhas e a verificação de autoria são automatizadas através da verificação do grau de similaridade das produções. Para tanto, é usada a técnica de inteligência artificial modelo vetorial de classificação de documentos e o algoritmo $k$ Nearest Neighbor $(\mathrm{kNN})$ para ensinar ao computador como classificar as resenhas dos alunos a partir de um conjunto previamente rotulado por especialistas humanos (BaezaYates; Ribeiro-Neto, 2011). Relativo à autoria, pretende-se inferir a porcentagem de quanto um aluno é coautor de uma produção coletiva, considerando a entrega individual, as interações em rede ocorridas e o texto base de trabalho.

\section{Descrição do Experimento}

Para validação da efetividade da AP proposta, um experimento foi realizado com o objetivo principal de compreender a evolução do aprendizado, os desafios e problemas enfrentados por alunos, professor e tutor para a realização de uma atividade cooperativa na modalidade a distância, de acordo com o tipo de atividade da AP e em disciplinas com grande número de alunos. Para viabilizar a AP, criamos um protótipo a partir de uma combinação (Figura 2) de facilidades fornecidas pelo Moodle e outras ferramentas externas que permitiram operacionalizar a execução de sua sistematização metodológica.

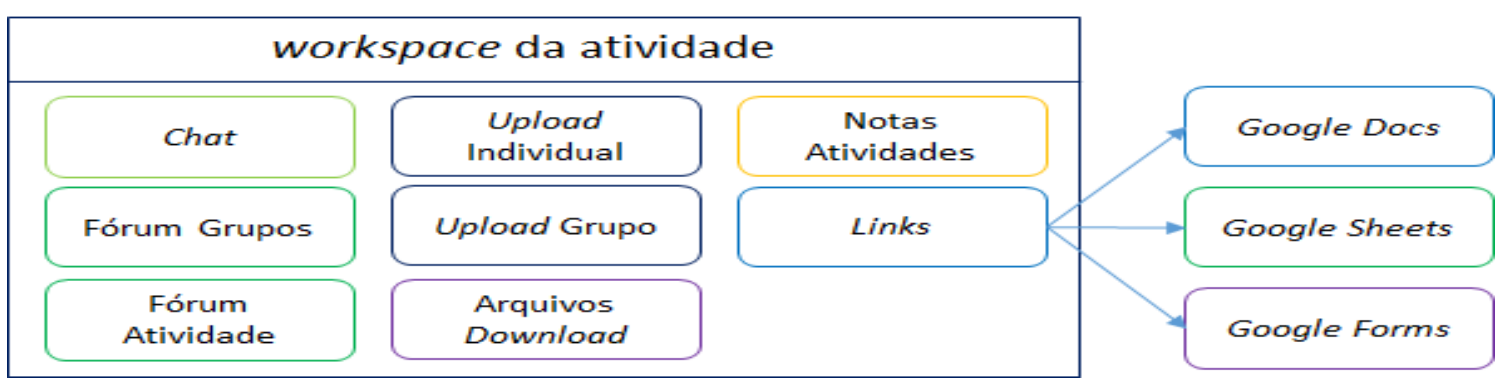

Figura 2: Protótipo de suporte computacional

Para o desenvolvimento do experimento, foi escolhida a disciplina de "Textos Científicos: aspectos metodológicos e linguísticos". Esta disciplina é ofertada de forma compartilhada e na modalidade a distância em diversos cursos presenciais numa instituição de ensino superior. O experimento foi conduzido da seguinte forma:

i) No Ambiente Virtual de Aprendizado (AVA) da referida disciplina, foi criado um workspace para o desenvolvimento da atividade. Nele, foram inseridos o texto base 
da atividade, o modelo de entrega da atividade, os requisitos avaliativos, os recursos de submissão das resenhas, os recursos de interação fórum e chat, os links de ferramentas externas e um tutorial (em texto e vídeo) sobre a atividade;

ii) Os estudantes, por livre iniciativa, formaram grupos. Para tanto, interagiram através de um fórum e preencheram os dados em uma planilha on-line;

iii) Cada integrante dos grupos produziu uma resenha individual a partir da leitura do texto base e fez o upload do arquivo no AVA;

iv) Através de discussões e reflexões e tomando por base as resenhas individuais, cada grupo produziu uma nova resenha para a atividade e fez upload do arquivo no AVA. Nesta etapa, os alunos interagiram através de um fórum específico;

v) A partir dos critérios disponibilizados, cada aluno avaliou a sua resenha individual e a do seu grupo. Por meio de um formulário on-line, os alunos fizeram uma autoavaliação e a avaliação de seus pares com relação à participação e qualidade das contribuições. Uma avaliação geral da atividade, fornecendo críticas, sugestões e recomendação foi feita;

vi) O tutor e o professor fizeram o levantamento das entregas, correção das resenhas coletivas e a contabilização das notas de cada aluno. As notas parciais foram registradas em planilha para o cômputo da nota final, a qual foi disponibilizada aos alunos, de forma individual, através de um recurso de nota no AVA. A pontuação atribuída à atividade foi de 2,0 pontos: elaboração da resenha individual e coletiva $(0,5)$; resposta ao formulário de avaliação $(0,5)$; correção da resenha coletiva feito pelo professor/tutor (até 0,5 ); e autoavaliação da resenha coletiva feito pelos integrantes do grupo (até 0,5).

\section{Resultados e Discussões}

O experimento foi realizado durante os meses de maio e junho de 2020. Na referida disciplina, estavam matriculados 539 alunos de diferentes cursos de graduação. Esta atividade foi de participação opcional e, do total de alunos, 181 (71 grupos) completaram todas as etapas previstas na atividade. A partir das respostas dos alunos, das correções das resenhas em grupo realizadas pelo tutor e do feedback fornecido pelo tutor e professor, foi possível realizar algumas análises que serão apresentadas a seguir.

A Tabela 1 traz um compilado das notas agrupadas por classes, relacionando a autoavaliação das notas das resenhas individuais e em grupo. Pela Tabela, pode-se constatar que houve uma reclassificação das notas pelas classes: 0,5 (100 para 137 => aumento de 37); >= 0,4 e $<\mathbf{0 , 5}$ (61 para $38 \Rightarrow$ diminuição de 23); >= 0,2 e $<\mathbf{0 , 4}$ (16 para 4 => diminuição de 12) e < $\mathbf{0 , 2}$ (04 para 02 => diminuição de 02). Na análise dos dados, verificou-se também que os alunos que atribuíram nota máxima para a resenha individual mantiveram a nota, e outros 37 que avaliaram com nota menor a resenha individual modificaram a avaliação, atribuindo nota máxima à resenha coletiva. Com relação à média das notas, para as resenhas individuais, a nota foi de $0,44 \mathrm{e}$, para as resenhas coletivas, a nota foi de 0,48 , um aumento de aproximadamente $09 \%$.

Levando em consideração a nota atribuída pelo tutor às resenhas coletivas, a média foi de 0,46. Comparando com a nota média atribuída pelos alunos às resenhas coletivas, houve um decréscimo de aproximadamente 4\%. A Tabela 2 traz um resumo do comportamento das notas para este cenário. 
IX Congresso Brasileiro de Informática na Educação (CBIE 2020)

Anais do XXXI Simpósio Brasileiro de Informática na Educação (SBIE 2020)

Tabela 1. Autoavaliação feita pelos alunos com relação às notas dos tipos de texto

\begin{tabular}{|c|c|c|}
\hline Classe de Notas & Resenha Individual & Resenha Coletiva \\
\hline 0,5 & 100 & 137 \\
\hline$>=0,4 \mathrm{e}<0,5$ & 61 & 38 \\
\hline$>=0,2 \mathrm{e}<0,4$ & 16 & 4 \\
\hline$<0,2$ & 04 & 2 \\
\hline
\end{tabular}

Objetivando mostrar a eficácia da cooperação para a evolução das notas dos alunos, a Tabela 3 traz um compilado por intervalo de percentual e percentual médio, das notas provenientes das correções feitas pelo tutor para as resenhas individuais e coletivas. Como a correção das resenhas individuais não estava prevista na sistematização metodológica da AP, optamos por fazer uma amostragem, escolhendo, aleatoriamente, um integrante de cada grupo para correção da resenha individual. Pela Tabela 3, constatase que houve aumento de nota (média de 14\%) para 50 alunos, representando $70 \%$ do número de alunos analisados. Para 19 deles, a nota se manteve e, para 02, houve uma pequena diminuição de nota. Extrapolando esta amostragem para o total de alunos que participaram da atividade (181), teríamos 126 com aumento de nota.

Tabela 2. Comportamento das notas entre autoavaliação e avaliação do tutor

\begin{tabular}{|c|c|}
\hline Número de Grupos & Comportamento das Notas \\
\hline 05 grupos & Decréscimo variando de $20 \%$ a $40 \%$, \\
\hline 13 grupos & Decréscimo variando de $08 \%$ a $10 \%$, \\
\hline 11 grupos & Decréscimo variando de $02 \%$ a $04 \%$ \\
\hline 13 grupos & Não houve alteração de nota \\
\hline 03 grupos & Acréscimo variando $15 \%$ a $20 \%$ \\
\hline 01 grupo & Acréscimo de $67 \%$ \\
\hline 25 grupos & Acréscimo na média de $04 \%$ \\
\hline
\end{tabular}

Relacionado com a autoavaliação e a avaliação de pares, os alunos foram questionados acerca de 04 indicadores: 01) Facilidade em expor suas opiniões; 02) Assertividade na proposição de contribuições para o desenvolvimento da atividade cooperativa; 03) Fundamentação dos argumentos de forma clara e coesa; e 04) Participação ativa em nível colaborativo, demonstrando interesse pela atividade. Para responder, os alunos usaram a escala likert de cinco pontos: $1=$ Péssimo; $2=$ Ruim; $3=$ Indiferente; 4 = Bom; 5 = Ótimo. Para uma melhor análise dos resultados, foi realizada uma abordagem quantitativa para estabelecer o Ranking Médio (RM) (Malhorta, 2001) para mensurar o grau de concordância dos sujeitos que responderam os questionários. Conforme observado na Tabela 04, a percepção dos alunos é bastante satisfatória, com todos os resultados acima de 4,5.

Quando questionados sobre se recomendariam esta atividade de natureza cooperativa para um colega, o indicador Net Promoter Score (NPS) (Reichheld, 2006), 
que considera a fidelidade do cliente a partir do seu potencial de recomendar um produto/serviço/marca, apresenta um resultado de 24,15 , indicando nível de aceitação razoável e que a atividade se encontra em nível de aperfeiçoamento. Esse resultado também está alinhado com alguns comentários de sugestões e críticas feitas pelos alunos, por exemplo: "melhor explicação sobre a atividade, recursos, etapas e datas de entrega"; "dificuldade em encontrar os recursos no AVA"; "dificuldade na formação de grupos, pois os alunos não se conhecem"; "dificuldade para elaborar o trabalho coletivo, pois parte do grupo não se esforçou para fazer o individual"; "preferência por atividade individual" (dado que os alunos não conseguiram se organizar para estabelecer discussões síncronas); "pouco envolvimento de parte do grupo"; "necessidade de estímulo à participação dos colegas para não prejudicar o grupo"; e, simplesmente, "preferência pelo trabalho individual".

Tabela 3. Avaliação do Tutor para as resenhas individuais e coletivas

\begin{tabular}{|c|c|c|}
\hline Número de Alunos & Intervalo de Percentual & Percentual Médio \\
\hline 12 & $20 \%$ a $50 \%$ & $30 \%$ \\
\hline 15 & $10 \%$ a $19 \%$ & $13 \%$ \\
\hline 23 & $6 \%$ a $9 \%$ & $6 \%$ \\
\hline 2 & $-8 \%$ a $-6 \%$ & $-7 \%$ \\
\hline 19 & Não houve alteração & \\
\hline
\end{tabular}

Por outro lado, ocorreram comentários positivos: "foi possível criar aproximação com colegas de diferentes cursos"; que "o desempenho do grupo, apesar da apreensão inicial, superou as expectativas"; que "a atividade proporcionou o surgimento de opiniões e pensamentos diferentes a partir de um mesmo objeto de estudo"; "possibilidade de evoluir a qualidade da produção" (dado a forma de produção individual e coletiva); e que "o formato da atividade auxiliou na fixação do conteúdo".

Tabela 4. Ranking Médio (RM) - Indicadores de autoavaliação e avaliação dos pares

\begin{tabular}{|c|c|c|}
\hline Indicador & RM - Autoavaliação & RM - Avaliação pares \\
\hline Indicador 01 & 4,67 & 4,56 \\
\hline Indicador 02 & 4,66 & 4,65 \\
\hline Indicador 03 & 4,61 & 4,52 \\
\hline Indicador 04 & 4,71 & 4,69 \\
\hline
\end{tabular}

Já com relação a nota geral da atividade, levando em conta todas as pontuações que a compõe, a nota média dos alunos foi de 1.9, de um total de 2.0.

\subsection{Considerações do Professor e do Tutor}

No que diz respeito à percepção do tutor e professor, os mesmos relataram que: os estudantes que fizeram a atividade completa conseguiram atingir o objetivo proposto; não houve total adesão dos alunos e que isso ocorreu, principalmente, pela atividade ter sido opcional; os estudantes ficaram confusos pela diversidade de ferramentas; houve dificuldade para identificar a participação dos alunos na etapa cooperativa, e de 
estabelecer contato para motivá-los; grande volume de trabalho para corrigir as entregas dos grupos e dar o feedback adequado; acham importante e necessário corrigir e dar o feedback para as resenhas individuais, mas que isso inviabilizaria a atividade; acham que muitos alunos ainda não têm maturidade para atribuir notas às suas produções e que a correção do professor é fundamental para validar as autoavaliações. Por último, mencionaram ser importante ter a possibilidade de identificar as contribuições individuais na entrega do grupo, a parcela de autoria e como se relacionam com as soluções individuais.

\section{Considerações finais}

Neste trabalho, apresentamos os resultados preliminares de uma AP que busca potencializar a construção do conhecimento a partir da elaboração de resenhas reflexivas, numa abordagem cooperativa, ativa e metacognitiva, levando em conta a produção individual em etapa preliminar.

A efetividade, os problemas e desafios relacionados à AP proposta foram analisados em um experimento tendo por base uma disciplina EAD com grande volume de alunos matriculados em diversos cursos presenciais de uma instituição de ensino superior. Do total de alunos (539), houve a participação de 181 e todos concluíram as etapas previstas. Pelos resultados obtidos, é possível constatar que a AP proposta pode potencializar a aprendizagem e melhorar a cooperação entre os alunos numa perspectiva multidisciplinar e a distância, favorecendo a aproximação e a comunicação entre os envolvidos, bem como o compartilhamento de informações e experiências.

Relativo à eficácia da cooperação para a evolução das notas (correção das resenhas individuais e coletivas feita pelo tutor), para $70 \%$ do número de alunos analisados, houve um aumento médio de $14 \%$. Comparando a autoavaliação dos alunos, resenhas individual e coletiva, na média, houve um aumento de $9 \%$ nas notas. Já a comparação da nota de autoavaliação da reposta coletiva com a avaliação do tutor, na média, houve um decréscimo de $4 \%$. De toda forma, a nota média das resenhas coletivas atribuída pelo tutor foi muito boa, acima de 0,4 (de um total de 0,5), confirmando a percepção de nota dos alunos. No que diz respeito à nota geral da atividade, levando em conta todas as pontuações que a compõe, a nota média dos alunos foi de 1.9, de um total de 2.0. A percepção dos alunos sobre a participação e qualidade das contribuições, tanto da autoavaliação, quanto da avaliação dos pares, é bastante satisfatória, com todos os resultados acima de 4,5, de um total de 5 .

Portanto, ficou evidenciado pelos resultados obtidos no experimento que a AP está proporcionando momentos importantes de troca de experiência e conhecimento. Além disso, demandou protagonismo por parte dos alunos, reconstrução de ideias gerando novos olhares para as produções individuais e, consequentemente, construções cooperativas com mais qualidade. Por fim, para que todos os envolvidos tenham condições mais favoráveis de desenvolver suas atividades e aproveitarem do potencial que a AP pode oferecer, torna-se necessário a implementação da solução computacional proposta, a qual será alvo de trabalhos futuros.

\section{Referências}

Alves, L. (2011) Educação a distância: conceitos e história no Brasil e no mundo. Revista Brasileira de Educação a Distância. v.10, n.7. 
Aragon, R. (2016) Interação e mediação no contexto das arquiteturas pedagógicas para a aprendizagem em rede. Revista de Educação Pública, 25(59/1), 261-275.

Baeza-Yates, R. e Ribeiro-Neto, B. (2011) Modern Information Retrieval. AddisonWesley, Wokingham, UK, 1999. Second edition published in 2011.

Barros, E. e Menezes, C. (2016) EsCola Ambiente Educacional para Escrita Colaborativa. In: Anais do Simpósio Brasileiro de Informática na Educação.

Carvalho, M. J. S., Nevado, R. A. e Menezes, C. S. (2005) Arquiteturas Pedagógicas para Educação a Distância: Concepções e Suporte Telemático. Anais do Simpósio Brasileiro de Informática na Educação.

Carvalho, M. J. S., Nevado, R. A. e Menezes, C. S. (2007) Aprendizagem em Rede na Educação a Distância - estudos e recursos para formação de professores. Lens - Porto Alegre/RS.

Castro, A. e Menezes, C. S. (2011) "Aprendizagem colaborativa com suporte computacional". In Pimentel M. e Fuks H. Sistemas Colaborativos, 135-153. ElsevierCampus-SBC.

Christensen, C. M. e Eyring, H. J. (2014) A universidade inovadora: mudando o DNA do ensino superior de fora para dentro. Porto Alegre: Bookman.

Collazos, C. A. et al. (2007) Evaluating collaborative learning processes using systembased measurement. In: Educational Technology \& Society, 10(3):257-274.

Ellis, C. A., Gibbs, S. J., and Rein, G. L. (1991). Groupware. Communications of the ACM, 34(1):39-58.

Fiusa, P. J. e Mocelin, R. R. (2017) "Arquiteturas Pedagógicas: revisão de conceitos e suas aplicações na educação brasileira". In: Proceedings of XXII Conferência Internacional sobre Informática na Educação (TISE), Fortaleza, Brasil.

Malhotra, N. (2001) Pesquisa de Marketing: uma orientação aplicada. Porto Alegre: Bookman.

Nevado, R. A., Menezes, C. S. e Vieira Júnior, R. R. M. (2011) Debate de Teses - Uma Arquitetura Pedagógica. Anais do Simpósio Brasileiro de Informática na Educação.

Parrat-Dayan, S. e Tryphon, A. (org). (1998) Jean Piaget: sobre a Pedagogia - Textos inéditos. Coleção Psicologia e Educação. Casa do Psicólogo.

Pedró, F. et al. (2019) "Artificial intelligence in education: challenges and opportunities for sustainable development.". UNESCO Working Papers on Education Policy, no. 5.

Piaget, J. (1985) O Possível e o Necessário: evolução dos possíveis na criança. v. 1 Artes Médicas. Porto Alegre.

Pimentel, M. e Fuks, H. (2011) Sistemas Colaborativos, Elsevier-Campus-SBC.

Reichheld, F. (2006) A pergunta definitiva, Editora Campus.

Russel, S. e Norvig, P. (1995) Artificial Intelligence-A Modern Approach, Prentice Hall, New Jersey, USA.

Scardamalia, M. e Bereiter, C. (2006). Knowledge building: Theory, pedagogy, and technology. In K. Sawyer (Ed.), Cambridge Handbook of the Learning Sciences (pp. 97-118). New York: Cambridge University Press. 